\title{
Editoríal.
}

\section{THE SCOPE OF NEUROLOGY IN HOSPITAL PRACTICE.}

THERE can surely be no one of us who is not at times troubled 1 as he reflects upon the smallness of his achierements in the practice of healing. And none perhaps is forced more often to a confession of his impotence than the neurologist in face of organic disease. For himself he may indeed gain some intellectual pleasure from the solution of nice problems in localization and pathological diagnosis. He may through years of patient research, correlating symptoms with signs, and both with post-mortem evidence, adrance our knowledge of the nerrous system and of the first signs of disease therein. Such work is of abiding value to humanity; yet eren in the achievement it may at times prove cold comfort to the practising physician; for in the majority of cases there is little he can do for the individual patient who seeks his aid. Syphilis of the nervous system, it is true, provides a group of satisfactory exceptions to the rule, but for the rest it is mainly a matter of bowing to the inevitable.

Small wonder that in a country less bound by traditional distinctions the neurologist seeks in the profession and art of surgery an outlet for his desire to help. In a recent review, Professor Harvey Cushing has summarized the advances made of late years in the field of neurological surgery, and has shown in his own practice the results both of amelioration and cure which may be obtained in certain cases. There is much to be said for such a combination of physician and surgeon's art in a single special branch of medicine; but in this country, for the present, prejudice is too strong against it. Moreover, one may safely predict that in exceptional cases only will men be found with a capacity for acquiring the technical skill required for both diagnosis and operative procedure. The former demands the training of a physician, the latter some experience of general surgery.

Looking, then, in other directions for the satisfaction of his humanitarian impulse, the neurologist may at any rate, in cases of functional nervous disease, find problems of immediate and practical importance to the individual patient. We should estimate that 
more than one-half of the persons who seek relief at the neurological out-patient department of a general hospital are suffering from functional as opposed to organic disease. Here is a challenge to therapeutic skill, and at the same time a problem of great difficulty. We have to deal now with symptoms depending not upon irreparable damage to fixed structures, but upon the reaction of labile forces of personality to environmental stresses.

Thanks largely to the stimulating force of Freud's work, there is a steadily extending belief that these patients need something more than a bottle of medicine and a few words of reassurance. We know that in most cases symptoms may be removed and suffering relieved by means of rational psychotherapy. Yet at the majority of general hospitals facilities for such treatment are sadly lacking. In this respect it behoves neurologists to realize their responsibilities, to demand and persistently demand that this defect be made good.

The chief need is for trained personnel both in the wards and in the out-patient departments. The number of men interested inthis branch of medicine is limited. The average house officer during his period of hospital appointments is too keenly occupied with the grosser problems of organic disease to be bothered with functional cases. It is only later, when he finds himself in practice, that he realizes with regret his inability, from lack of training, to cope with the multitude of 'neurasthenics' that throng his surgery.

As a first measure, let us ask for the appointment at each of the large hospitals of a resident house officer for the department of nervous diseases. This appointment should preferably be open to men who have already held the post of house physician or house surgeon. We have no doubt that suitable candidates would be forthcoming.

Tracing to its source the general want of knowledge of this subject among medical students, let us next plead for the introduction of lectures on the elements of psychology into the year's course of anatomy and physiology. These, we feel sure, would attract large audiences, would interest the many and stimulate the few, who, as senior men, would develop into capable clinical assistants.

Finally, let us demand small neurological wards, male and female, in charge of a nursing staff who will take an active interest in these difficult patients-wards in which a tradition of sympathy and understanding will arise, and in which the sister handing over to the head nurse will no longer say with a shrug of the shoulders that "Number 12 is only functional".

In such matters we are far behind the best general hospitals of the United States. The recent formation in this country of a National Council for Mental Hygiene marks a step forward in principle. Under its xgis we hope that the reforms which we have 
outlined will be put into execution within the next few years. The united support of all neurologists holding hospital appointments will be necessary to this end, and this, we should take it for granted, would be forthcoming were it not for a regrettable fashion in certain neurological circles to let pass no opportunity for decrying the cult of clinical psychology.

It is of no use for the neurologist to disclaim responsibility for this work on the plea that it belongs to the province of the psychiatrist. In the phraseology of the lay public, these patients are 'suffering from nerves', and it is to the department for nervous diseases that they come, and will continue to come, in their hundreds. 